\title{
Parental Knowledge and Practices on Preschool Children Oral Healthcare in Nibong Tebal Penang, Malaysia
}

\author{
Nur Alya Fatin Abu Bakar ${ }^{1}$ and Zakira Mamat ${ }^{2 *}$ \\ ${ }^{1}$ Bachelor of Nursing Sciences, School of Health Sciences, Universiti Sains Malaysia \\ ${ }^{2}$ Nursing Programme, School of Health Sciences, Universiti Sains Malaysia, Health Campus 16150 Kubang Kerian, Kelantan, Malaysia
}

Submission: April 19, 2018; Published: April 26, 2018

*Corresponding author: Zakira Mamat, Nursing Programme, School of Health Sciences, Universiti Sains Malaysia, Health Campus 16150 Kubang Kerian, Kelantan, Malaysia, Tel: +6019-9326332; Email: zakira@usm.my

\begin{abstract}
Background: Children under the age of six generally spend most of their time with parents who play a central role in giving education and encouragement to children for healthy oral condition. Preschool children oral healthcare is influenced by their parents knowledge and practices.

Purpose: This study aimed to identify the parents' level of knowledge and practices done on preschool children oral healthcare in Nibong Tebal, Penang.

Methodology: A total of 230 parents whose children aged between 4-6 years old and receiving an early education in 11 randomly selected Taman Bimbingan Kanak-kanak Jabatan Kemajuan Masyarakat (TABIKA KEMAS) TABIKA KEMAS in Nibong Tebal district were participated in this study. A 19-item questionnaire covering socio-demographic characteristics, knowledge on preschool children oral health care and the practices done by the parents was distributed to each parent.

Result: As much as $72.2 \%$ of parents possessed good knowledge whereas $27.8 \%$ classified as fair. The mean age of parents with fair knowledge (37.86, SD 6.54) was not much older than the parents with good knowledge (37.08, SD 6.55). In addition, parents with higher educational level were found significantly had better level of knowledge on preschool children oral health care $(\mathrm{p}=0.001)$.

Conclusion: Age is not the determinant factor for parental level of knowledge on preschool children oral healthcare. However, their educational level greatly influences their level of knowledge. Therefore, parents need to be encouraged through the development and implementation of preschool children oral healthcare program and health promotional activities, regardless of their age and level of education. Keywords: Parental Knowledge; Practices Preschool Children; Oral Healthcare

Abbreviations: MOH: Ministry of Health Malaysia; ECC: Early Childhood Caries; WHO: World Health Organization
\end{abstract}

\section{Introduction}

\section{Background/Rational}

Oral health was given a considerable importance not only in Malaysia, yet during the last decade and it is an integral part of general health in infants and children. Oral healthcare affects the quality of life and health outcomes. According to WHO [1], oral health is a condition that free from chronic mouth and facial pain, oral and throat cancer, oral sores, birth defects, periodontal disease, tooth decay and tooth loss, and other diseases that affect the oral cavity. Meanwhile, Oral Health Division of Ministry of Health Malaysia (MOH) (2011) defines optimum oral health as standard of health that free from active disease which contributes to general well-being in a state that enables a person to eat, speak, socialize and undergo activities of daily living without pain, discomfort or embarrassment. Children who have dental caries at the early age can be considered to have early childhood caries (ECC). ECC can be described as the presence of one or more decayed tooth, missing due to caries, or filled surfaces in any primary tooth in a child age 6 years or younger. Children who experience ECC are predicted to have three folds of chances for their permanent teeth to be developed with caries compared to those who do not experience ECC (Oral Health Division of MOH, 2011). Tooth decay that leads to dental caries can develop as soon as the first tooth appears. The good news is that tooth decay is preventable. For that purpose, appropriate measures must be taken as early as possible since early childhood is a period where primary teeth erupt, bacteria colonise tooth surfaces and dental behaviour starts to develop. Moreover, children's education for oral health begins very early in life, through the primary socialization process. Oral healthrelated concepts and behaviours are further adopted throughout life during the formative pre-school years when the child's caries pattern and risk are established. Therefore, early childhood is 
an important period for instituting good oral health practices in children.

\section{Objectives}

The general objective of this study is to determine the level of knowledge and practices among parents on preschool children oral healthcare. The specific objectives are to identify the level of knowledge on preschool children oral healthcare among parents in Nibong Tebal, Penang and to identify the practices done by parents on preschool children oral healthcare.

\section{Methodology}

Ethical consideration (USM Research ID: 116299) taken before study done. Prior to answering the questionnaire, the researcher explained the purpose of the study to eligible respondents which in this study were parents. Parents who were willing to participate in the study had given oral or written consent. Then, they received further explanation about the study.

\section{Study Design}

The research design used in this study was cross-sectional design of quantitative study. The data was obtained through a questionnaire consisted of a set of multiple choice questions and Likert-scale questions. This was a useful way to gather information on sociodemographic data; parents' age, gender and educational level; as well as level of knowledge and practices done to their preschool children oral health care in Nibong Tebal, Penang, Malaysia.

\section{Participants}

The target or theoretical population in this study was population of parents whose children were aged four to six years old in Nibong Tebal, Penang. The study or accessible population were chosen from parents of preschool children who were receiving an early education in one of the kindergartens under Taman Bimbingan Kanak-kanak (TABIKA) Jabatan Kemajuan Masyarakat (KEMAS), in Nibong Tebal district. There were a total of 33 TABIKA KEMAS altogether which made the total number of children receiving early education in kindergarten in Nibong Tebal was approximately 560 children. The sampling size for this research was identified using the Raosoft sample size calculation software. It was applied to ensure the accuracy by avoiding sampling error during representative and parameters of the sample with a confidence level at $95 \%$ and a margin of error that can be tolerated at 0.05 . With the population size of approximately 560 of children attending 11 out of 33 TABIKA KEMAS in Nibong Tebal from January to December 2016 and the response distribution of $50 \%$, thus the minimum recommended sample size for the this study was 229 samples. Nearly almost all respondents agreed that dental visit is necessary regardless of the health of the children's teeth (99.6\%) and food plays an important role in the health of children's teeth (99.1\%). Significantly more parents believed that breast-feeding is better than artificial feeding $(97.4 \%)$ meanwhile $0.9 \%$ and $1.7 \%$ of respondents were disagreed and not knowing respectively.

On the knowledge of first tooth emergent, 9.6\% not knowing when the first tooth emerges, $87 \%$ knew that it emerges before a child reaches one year old but $3.5 \%$ of respondents disagreed. Only nearly half $(47.8 \%)$ of the respondents agreed that it is possible for tooth to return to normal condition after caries while more than one quarter of respondents disagreed (26.1\%) and $26.1 \%$ reported not knowing.

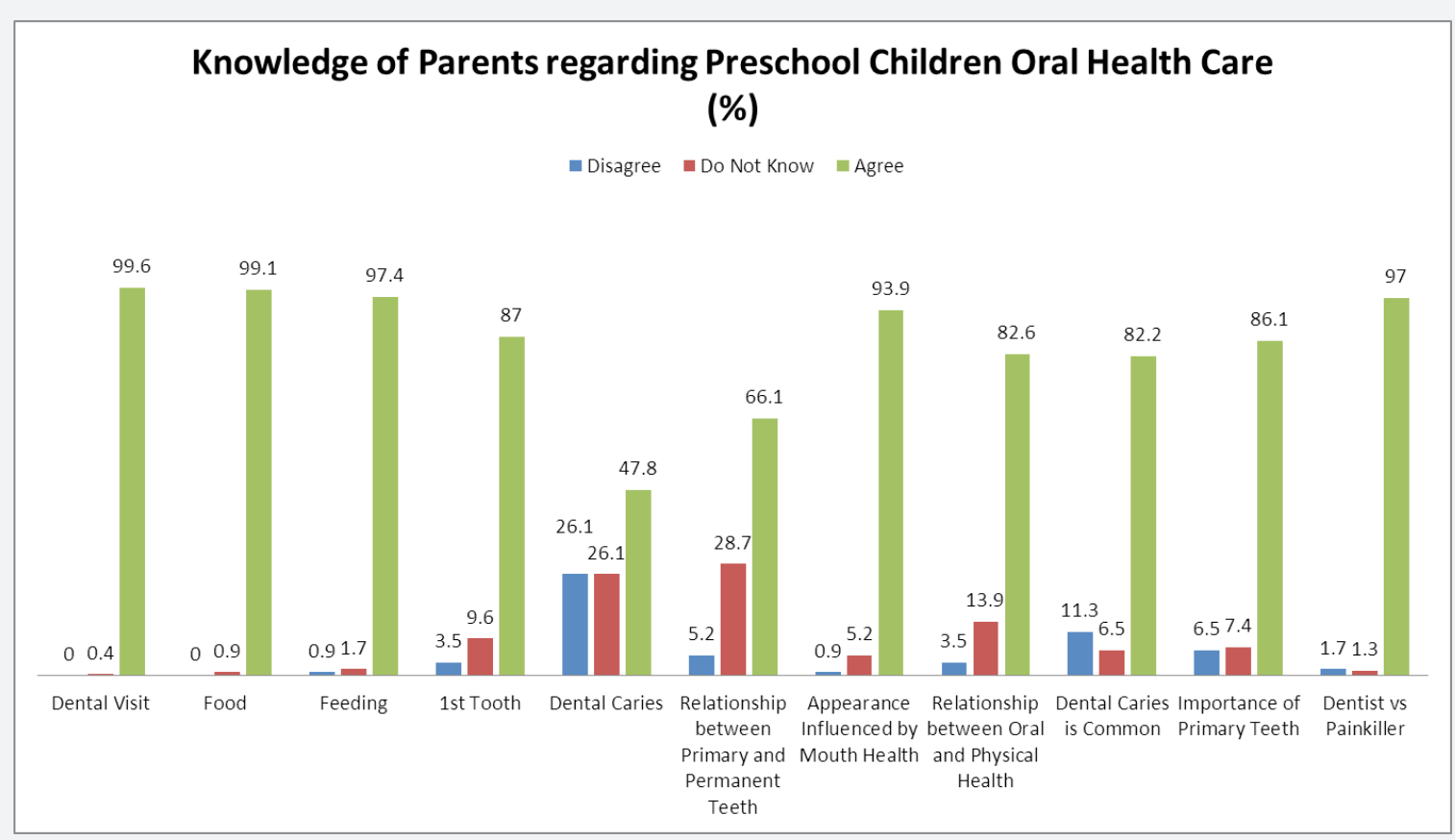

Figure 1: Likert-scale Question Responses on Knowledge of Parents on Preschool Children Oral Healthcare. 
More than half (66.1\%) of the respondents had thoughts that there is a relationship between primary teeth and permanent teeth. However, there were still a considerable proportion of respondents who did not know about the relationship whereas $5.2 \%$ of them were totally disagreed. Majority of respondents (93.9\%) agreed, 5.2\% not knowing and only 0.9\% disagreed on the fact that the children's appearance in the future is influenced by their mouth health. A total of 190 respondents agreed that oral health of the child has relationship with his/her physical health in the future while $82.2 \%$ respondents agreed that dental caries is common in Malaysia children despite of $11.3 \%$ and $6.5 \%$ respondents disagreed and did not know respectively (Figure 1). Most of respondents (86.1\%) and (99.1\%) thought that primary teeth are as important as permanent teeth and going to the dentist was better than the use of painkiller of toothache respectively. From the overall questions to determine the level of knowledge among parents on preschool children oral healthcare, 166 parents representing $72.2 \%$ had good knowledge while the rest $27.8 \%$ had fair knowledge. None of the parents were categorised in poor knowledge. Figures 2 shows the parents' level of knowledge of overall questions asked on their knowledge.

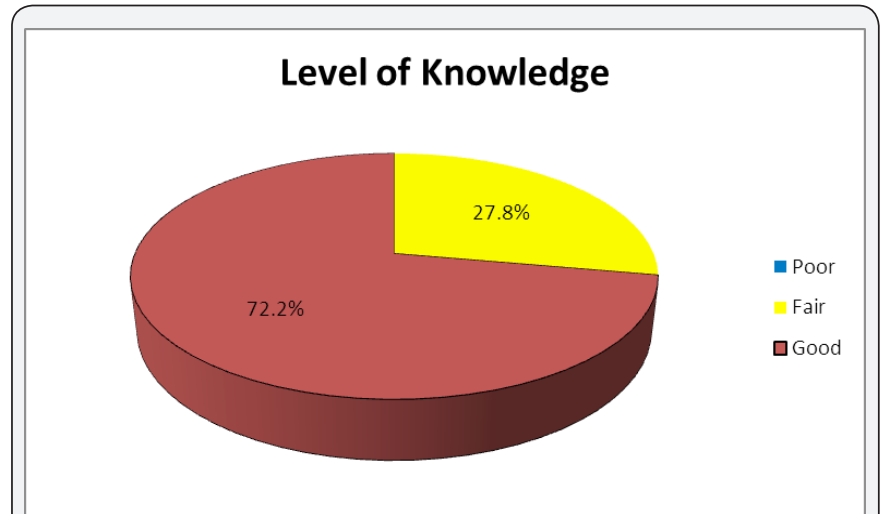

Figure 2: Parents' Level of Knowledge on Preschool Children Oral Healthcare.

\section{Discussion}

Majority of the parents participated in this study scored 'good' (72.2\%) and 'fair' (27.8\%) level of knowledge with no one scored 'poor'. There are many factors that may contribute parents to score 'good' level of knowledge such as economic status, attitudes, oral health literacy, education and behaviour. In this case, one of the reasons they scored 'good' level of knowledge may be because of the attitudes of the parents who have awareness and efforts to gain knowledge on preschool children oral healthcare. Even though they were from rural area, it did not mean that they were left behind from the updates of knowledge from oral health promotion programs organised by Dental Health Team in community. Besides, they were actively involved in those programs not only for their preschool children oral health but also theirs. Another factor that may support their good level of knowledge is their experiences and practices taught them indirectly on preschool children oral healthcare. Even though they did not read much, but the lessons they got from their ancestors, oral health practices they done to themselves and their experiences on their previous children oral healthcare helped them in gaining knowledge. In this section, 11 questions were asked which can be categorised into 4 subsections representing dental visit, diet and dietary practices, importance of primary and permanent teeth, and dental caries.

Visit the dentist on a regular basis, at the minimum once a year is very important which will catch problems early on, such as tooth decay, gum disease, cavities or even oral cancer. The earlier the tooth problem is diagnosed, the easier it is to treat. Six months is the ideal time frame to go in for a regular checkup. In the previous study by Ashkanani \& Al-Sane (2012) shows that only $24.6 \%$ of caregivers answered correctly on the ideal time for dental visit. In the present study, almost all the parents (99.6\%) know the fact that dental visit is necessary regardless of the health of the child's teeth. However, study conducted by Shetty [2] found that $59.3 \%$ of mothers would visit a dentist only if a caries is detected in the child's teeth. A large proportion of parents (99.1\%) of respondents agreed that food plays an important role in the health of the mouth and teeth of the children. A study by Reang and Bhattacharjya [3] and Suresh, Ravishankar, Chaitra, Mohapatra, \& Gupta (2010) reported almost the same result. This finding also was in line with the finding of the study done by Shetty [2] which was $87 \%$ of the mother had good knowledge about dietary and feeding practices. It was observed from the different studies that food affects the oral health similar to the present study. In the study, $87 \%$ of parents agreed that first tooth emerges before a child reaches one year as well as they aware that the tooth might be attacked by caries as young as six month old as found by Chia, Densie [4] On the other hand, the questions with the most uncertain answers were whether it is possible for tooth to return to normal condition after caries (item number 5) and whether there is a relationship between primary and permanent teeth (item number 6). More than quadrant of the parents answered 'I don't know' to both questions with $26.1 \%$ and $28.7 \%$ respectively. These results showed that the parents have low knowledge on the importance of primary teeth which in line with study conducted by Suresh et al. (2010).

This study found that $86.1 \%$ of parents thought that primary teeth are as important as permanent teeth which in line with study by Shetty [2] that found $71.7 \%$ of parents acknowledged the importance of the primary teeth as they concerned for permanent teeth. They believed that cavities in primary teeth should be treated, since they can lead to further caries in permanent teeth. On the other hand, it was contradictory to the findings of Chhabra (2012) that reported the parents believed that primary teeth are present in mouth temporarily and will be replaced by permanent teeth. Children are more susceptible to caries when parents ignored the important of primary teeth or paid less attention toward decay of these teeth. The feeding practices done by the parents in this study mostly had both breast and artificial feeding to their children with $62.2 \%$. In addition, breast feeding or artificial feeding alone had only little differences in frequency with 
$20 \%$ and $17.8 \%$ respectively. This findings had different results from the study done by Shetty [2] which suggested that more than half $(55.2 \%)$ of the parents fed their children through breast feeding alone compared to both breast and bottle feeding (33.7\%) and artificial feeding alone (11.1\%). The contrary results between these two studies might be due to variation of children's age in the studies. The current study targeted preschool children aged between 4-6 years old whereas Shetty [2] recruited children aged 1-6 years old. By both breast and artificial feeding, current study found higher prevalence which could be explained by most of 4-6 years old children no longer had breast feeding at that age. All the children already weaned off from breast feeding approximately in the age of 2 years old and continue consuming milk through artificial feeding. However, Shetty [2] had higher prevalence of breast feeding due to the children recruited were aged 4.30 years old in average.

Parents had various answers in response to the questions that asked about their attention to the health of their child's mouth. $1.3 \%$ claimed that they paid attention only if there is any complaint from their child while $5.2 \%$ done that after several days after birth. Besides, this study had majority (51.3\%) of parents who paid attention after the first tooth emerged and supported the study done by Gussy et al. (2008) but in contrary with the study by Suresh et al. (2010) that suggested parents starts to brush their child's teeth when all the primary teeth have emerged. Majority (45.2\%) of the parents in this study brushed their child's teeth twice daily which was in line with the findings by Chhabra (2012) with $41.3 \%$ but not as much as the majority in the study found by Shetty [2] with $80.5 \%$ and Ashkanani \& Al-Sane (2013) with $80 \%$ of the parents. As much as $8.7 \%$ of parents in this study claimed that they brush their child's teeth once daily. This finding supported other previous studies done by Shetty [2] and Pullishery, Panchmal \& Shenoy [5] with $14.5 \%$ and $78.4 \%$ of the parents acknowledged brushing their child's teeth once daily respectively.

However, in other response to the question, it was a big contrast which $42.2 \%$ of the parents in this study clean their children's mouth every time after fed compared to only 5\% reported by Shetty [2]. There was no known reasons explained why such conditions occurred. It is whether there was some misinterpretation regarding the questions or due to some social desirability influenced parents to choose the answers they believed to be correct rather than the actual practice, or maybe they really practice in that way. The study conducted by Machry, Tuchtenhagen, Agostini, Silva Teixeira, Piovesan, Mendes \& Ardenghi (2013) demonstrated that a high proportion of preschool children in Brazil had never visited a dentist. In addition, previous report by Reang and Bhattacharjya [3] found that 95.9\% of mothers did not attend dentist for their children dental problem. The findings were not in accordance with this study which practice on dental visit was found very good as almost all parents would bring their child to seek dental treatment if there was a complaint of pain, whether it was general dentist or pediatric dentist represented by $24.8 \%$ and $69.6 \%$ of parents respectively. However, it is worth a further research to investigate whether the practice of dental visit is associated with parents' perception of the need for a preventive appointment, or whether parents only bring their children to the dentist following the emergent of symptoms or complaint of pain. Regarding the preference of the parents towards dentist, majority of parents $(60.9 \%)$ chose the closest public or private dentist over top quality dentist (13.9\%) or dental specialist (23.9\%). This is because, in rural area such as Nibong Tebal, there is little number of good dentists available. If there is, the cost is quite high which is not affordable for parents who have low income. Therefore, they prefer the closest public or private dentist but not the cheapest as they still want to give the best and quick treatment to their children [6-9].

\section{Conclusion}

This study revealed that majority parents had good knowledge regarding their preschool children oral health care regardless of their residency whether it is in rural or urban area. Besides, the findings indicated that the parents applied good oral care practices towards their children. Parents, regardless of their age, need to be helped through development and implementation of wide-scaled, long term community health education program and health promotional activities since there are no difference between younger and older populations. This study also demonstrated that the higher the parents' educational level the better their level of knowledge on preschool children oral health care. However, regardless of the educational level, the researcher believes that improvement of oral health care knowledge would likely to improve the effectiveness of future oral health programs $[10,11]$.

\section{Acknowledgement}

My appreciation to Universiti Sains Malaysia, Jabatan Kebajikan Masyarakat (KEMAS), Taman Bimbangan Kanak-kanak (TABIKA) \& Dr. Dariah Mohd Yusoff as a course coordinator for research project, for giving me permission to conduct this study.

\section{References}

1. World Health Organisation (WHO) (2015) Oral health.

2. Shetty RM, Deoghare A, Rath S, Sarda R, Tamrakar A (2016) Influence of mother's oral health care knowledge on oral health status of their preschool child. Saudi Journal of Oral Science 3(1): 12-16.

3. Reang T, Bhattacharjya H (2014) Mother's knowledge and practice regarding oral Hygiene and challenges in the prevention of dental caries of under-five children in an urban resettlement colony. International Journal of Medical Science and Public Health 3(1): 76-80.

4. Chia L, Densie I, Morgan C (2015) An exploratory study of parental knowledge of early childhood oral health care in Southland, New Zealand. The New Zealand Dental Journal 111(1): 18-24.

5. Pullishery F, Panchmal G S, Shenoy R (2013) Parental attitudes and tooth brushing habits in preschool children in Mangalore, Karnataka: A cross-sectional study. International Journal of Clinical Pediatric Dentistry 6(3): 156-160.

6. Al Darwish M, Mohammed Abuhassna, Sameer A Al Thomairy (2015) Oral Health Knowledge and Sources of Oral Health Information among 
School Children in Qatar. Journal of Dental Health, Oral Disorders \& Therapy 2(3).

7. Alshehri A, Nasim V S (2015) Infant oral health care knowledge and awareness among parents in Abha city of Aseer Region, Saudi Arabia. The Saudi Journal for Dental Research 6(2): 98-101.

8. Finnegan D A, Rainchuso L, Jenkins S, Kierce E, Rothman A (2015) Immigrant caregivers of young children: Oral health beliefs, attitudes, and early childhood caries knowledge. Journal of Community Health 41(2): 250-257.

This work is licensed under Creative Commons Attribution 4.0 License DOI: 10.19080/JOJNHC.2018.07.555716
9. Qiu RM, Wong MC, Lo EC, Lin HC (2013) Relationship between children's oral health-related behaviors and their caregiver's sense of coherence. BMC Public Health 13(1): 239.

10. Rustvold, Susan Romano (2012) Oral Health Knowledge, Attitudes, and Behaviours : Investigation of an Educational Intervention Strategy with At-Risk Female. Unpublished dissertation of Doctorate of education, Portland State University.

11. Xiao Li Gao XL, Mcgrath C, Lin HC (2011) Oral health status of ruralurban migrant children in South China. International Journal of Paediatric Dentistry 21(1): 58-67.

\section{Your next submission with Juniper Publishers will reach you the below assets}

- Quality Editorial service

- Swift Peer Review

- Reprints availability

- E-prints Service

- Manuscript Podcast for convenient understanding

- Global attainment for your research

- Manuscript accessibility in different formats

( Pdf, E-pub, Full Text, Audio)

- Unceasing customer service

Track the below URL for one-step submission https://juniperpublishers.com/online-submission.php 